\title{
Is fast track rehabilitation already standard in gastrointestinal surgery?
}

\author{
R. Kafka-Ritsch
}

Published online: 4 March 2015

(C) Springer-Verlag Wien 2015

Fast track rehabilitation in colorectal surgery developed and introduced by Kehlet et al. during the mid-1990s changed the strategy of perioperative treatment breaking with a lot of dogmas like preoperative fasting and bowel preparation $[1,2]$. The aim of this novel strategy was to reduce surgical stress response, minimize the fasting period, and the time of immobilization of the patient. As a consequence, early restoration of bowel function and reduced perioperative morbidity allowed early discharge from hospital [3]. Initially this was postulated as one of the most important goals of the program. Subsequently "ERAS" (Enhanced Recovery after Surgery) replaced the term "Fast track" to refer the aim of the program to early recovery and reduced perioperative complications [4].

Fast track as a synonym for modern perioperative treatment was discussed in the majority of surgical congresses. Asking surgical colleagues if they do fast track at their department resulted frequently in agreement. So we could easily presume that fast track is already standard in the majority of surgical wards. But discussing the details of the fast track recovery program, listening to presentations of fast track experiences or analyzing recent papers published on this issue, you can recognize, that there are no clear definitions about the essential elements to fulfill for the definition of a fast track recovery program and on the other hand the degree of fulfillment remains unsatisfactory. Moreover different institutions seem to have their own interpretation of fast track by changing ore selecting elements of the fast track protocol $[5,6]$.

For example, in a publication of Quan Wang et al. about the effect of fast track surgery in laparoscopic colorectal surgery in patients $>65$ years the authors tell

R. Kafka-Ritsch $(\square)$

University Hospital Innsbruck, Anichstrasse 37, 6020 Innsbruck, Austria

e-mail: reinhold.kafka-ritsch@uki.at us: The fast track protocol included no preoperative mechanical bowel irrigation [7]. Nevertheless in methods the authors describe their method of bowel preparation as: "Oral administration of 2 bags of polyethylene glycol-electrolyte powder dissolved in $2000 \mathrm{ml}$ of warm boiled water one day before surgery; No administration of intestinal antibiotics; No mechanical bowel irrigation." This would be the standard bowel preparation done in conventional perioperative treatment at our department. Oral selective bowel decontamination with antibiotics and additional enemas as applied in their conventional group is rarely applied in conventional preoperative care for elective colorectal surgery in European hospitals. But this paper was published as a fast track trial and is integrated in a meta-analysis [8].

In order to establish essential elements the question was raised: Which components have been proven to have a positive effect on the rehabilitation of the patients? M.S. Vlug et al. addressed their study to this question analyzing the LAFA-trial database [9]. The examined 19 fast track elements in regard to correct application and therefore analyzed their influence on the primary outcome parameters, which was the length of hospital stay in this study. Their general conclusion was: "Evaluating only those fast track elements that were successfully achieved, enforced advancement of oral intake, early mobilization, laparoscopic surgery and female sex were independent determinants of early recovery." So they could not identify an effect of some "essential" elements as bowel preparation, preoperative carbo-loading, epidural analgesia, or intraoperative fluid restriction. A total of 19 elements of ERAS were reviewed for their level of evidence by Kristoffer Lassen in Archives of Surgery 2009 and Gustafsson reported an update of evidence in ERAS from a consensus meeting of the ERAS Society 2013 [10, 11].

On the other hand, Hasenberg et al. published a survey asking all Austrian and German surgical departments about the current practice of perioperative management 
in colonic and rectal surgery [12]. The response rate was low with $30 \%$ in Germany and acceptable with $67 \%$ in Austria. Interestingly, one of the most negated evidence in surgical literature was the data about preoperative bowel preparation. Although, no benefit of preoperative bowel preparation has been proven in several randomized multicenter trails with large patient populations and in a meta-analysis, more than $60 \%$ of surgeons still prefer to prepare their patients. This corresponds to an evaluation of the compliance with elements of the fast track protocol in our department published in this issue. Especially in laparoscopic surgery, surgeons argue that laparoscopic handling of stool-filled bowel leads to a higher risk of rupture. In left-sided resections transanal stapling requires an empty rectum. To our opinion this can be reached by an enema the evening and $2 \mathrm{~h}$ before surgery. Nevertheless, only $20 \%$ of surgeons in Austria and $10 \%$ of surgeons in Germany relied on this form of bowel preparation. Furthermore, the development of new methods in minimal invasive surgery with extraction of the resected bowel through minimal incisions or even transanal could be complicated by a stool-filled bowel. Until now no significant benefit of new minimal invasive approaches (single incision laparoscopic surgery or reduced port surgery) over "conventional" laparoscopy has been demonstrated in randomized trials [13-15].

On the other hand the spread of the fast track protocol has changed many items in perioperative care without establishing a real protocol [16]. So most of the surgeons are reducing the insertion of drains and allow their patients at least oral intake of clear liquids postoperatively. Early mobilization out of bed is already standard.

In regard to preoperative oral nutrition even in published fast track trials oral intake is often limited to liquids with the goal to avoid i.v. fluid administration. Starving overnight is nearly extinguished and carbo-loading with up to $500 \mathrm{ml} \mathrm{2-3} \mathrm{h}$ before surgery is well accepted by the surgeons and nearly all anesthetists. Guidelines of anesthetists societies already changed their recommendations for preoperative fasting [17].

In regard to epidural anesthesia the compliance by the patients and anesthetists, and the quality of the procedure is mandatory. The reported rate of successful, applied and over a period of $24 \mathrm{~h}$ functioning epidural anesthesia is low [18-22]. On the other hand even promoters of Fast Track recovery programs are questioning the need and cost/risk benefit of epidural anesthesia in laparoscopic surgery [23]. Moreover in laparoscopic surgery strategies to minimize the size or number of ports and to avoid the mini-laparotomy for the extraction of the specimen are published. Local infiltration with long acting local anesthesia or even retarded releasing of subcutaneously applied local anesthesia could achieve sufficient pain control as described in the later published data of a retrospective analysis. As mentioned above, epidural anesthesia had no impact on early discharge in the data from the LAFA trial [9]. Even in conventional colonic resection a transverse abdominal block is suggested instead of a thoracic epidural anesthesia [23, 24].
Failure to demonstrate an effect on faster recovery also was seen for intraoperative fluid restriction and still is questioned by many anesthesiologists. A study by M. Abraham-Nordling et al., showed no effect on early discharge but observed a higher rate on postoperative complications, especially major surgical complications as anastomotic leakage, in the group of normal fluid administration [25]. On the other hand 2 patients out of 79 suffered from postoperative renal dysfunction and 5 patients out of 79 experienced cardiac complications in the group of restricted fluid administration. Unfortunately, many published fast track trials do not give exact information about the amount and quality of intraoperative applied liquids. Moreover, a recent meta-analysis could not demonstrate a benefit of goal-directed fluid management by trans-esophageal Doppler echocardiography to conventional fluid therapy [26]. In a retrospective analysis of our patients, published below, we could not demonstrate an effect on postoperative bowel movement, tolerance of oral food and early discharge, but observed a higher rate of intraoperative bleeding in the group of patients with higher administration of intraoperative intravenous fluids.

Early mobilization of the patient seems to be accepted in a modified manner as mobilization on the day of surgery is not done routinely and a strict order to stay out of bed except for $2 \mathrm{~h}$ at midday as proposed by Kehlet is rarely accepted by patients and nursing staff. Maybe due to a lack of documentation or low rate of compliance this element is not investigated in detail. What is the real goal of fast track rehabilitation? Forced discharge on day 2 as proposed by Kehlet in the first studies is influenced by economic considerations. In many European countries early discharge is not compensated financially [27]. Therefore, it does not make sense to force early discharge of patients as nursing capacities are historically calculated on a mix of early postoperative patients with intensive nurse care and patients recovering from surgery more than 5 days ago with less workload for the nursing staff. So a fast track protocol with forced discharge 2 days after surgery will reduce financial compensation and augmenting the workload for the nursing staff. Moreover, compliance of the patients and their relatives with enforced early discharge is questioned and the fear for claims in case of complications and readmissions is raised in some discussions and level of evidence for early discharge is $C$ [22].

Nevertheless, the important advantages of fast track recovery is the reduction of complications, improvement of quality of life, and early recovery of the patient. Fast track research could demonstrate that many perioperative procedures such as fasting or bowel preparation are useless and can safely be omitted and protocols can be adapted in different surgical procedures [8]. So ERAS protocols have been established for various gastrointestinal resections, for example, for the resection of the esophagus as published below $[28,29]$. 


\section{Conclusion}

Fast track surgery programs have changed many perioperative procedures in daily praxis of gastrointestinal surgery, but some elements despite of scientific literature are persistently neglected by many surgeons and others like epidural anesthesia are replaced. In order to establish fast track recovery already as standard procedure, definition of essential elements to fulfill, exact definition of some of these elements, and adaptation to less invasive laparoscopic techniques require further investigation [27].

\section{Conflict of interest}

The author declares that there is no conflict of interest.

\section{References}

1. Kehlet H. Multimodal approach to control postoperative pathophysiology and rehabilitation. Br J Anaesth. 1997;78(5):606-17.

2. Wilmore DW, Kehlet $\mathrm{H}$. Management of patients in fast track surgery. Br Med J. 2001;322:473-6.

3. Kehlet $\mathrm{H}$, Mogensen T. Hospital stay of 2 days after open sigmoidectomy with a multimodal rehabilitation programme. Br J Surg. 1999;86:227-30.

4. Wind J, Polle SW, Fung Kon Jin PH, Dejong $\mathrm{CH}$, von Meyenfeldt MF, Ubbink DT, Gouma DJ, Bemelman WA. Laparoscopy and/or Fast Track Multimodal Management Versus Standard Care (LAFA) Study Group, Enhanced Recovery after Surgery (ERAS) Group. Systematic review of enhanced recovery programmes in colonic surgery. $\mathrm{Br} \mathrm{J}$ Surg. 2006;93(7):800-9.

5. Lyon A, Payne CJ, Mackay GJ. Enhanced recovery programme in colorectal surgery: does one size fit all? World J Gastroenterol. 2012;18:5661-3.

6. Hui V, Hyman N, Viscomi C, Osler T. Implementing a fasttrack protocol for patients undergoing bowel resection: not so fast. Am J Surg. 2013;206(2):152-8.

7. Wang Q, Suo J, Jiang J, Wang C, Zhao YQ, Cao X. Effectiveness of fast-track rehabilitation vs conventional care in laparoscopic colorectal resection for elderly patients: a randomized trial. Colorectal Dis. 2012;14:1009-13.

8. Ansari D, Gianotti L, Schröder J, Andersson R. Fast-track surgery: procedure-specific aspects and future direction. Langenbecks Arch Surg. 2013;398(1):29-37.

9. Vlug MS, Wind J, Hollmann MW, Ubbink DT, Cense HA, Engel AF, Gerhards MF, van Wagensveld BA, van der Zaag ES, van Geloven AA, Sprangers MA, Cuesta MA, Bemelman WA. Laparoscopy in combination with fast track multimodal management is the best perioperative strategy in patients undergoing colonic surgery: a randomized clinical trial (LAFA-study). Ann Surg. 2011;254:868-75.

10. Lassen K, Soop M, Nygren J, Cox PB, Hendry PO, Spies C, von Meyenfeldt MF, Fearon KC, Revhaug A, Norderval S, Ljungqvist O, Lobo DN, Dejong CH, Enhanced Recovery After Surgery (ERAS) Group. Consensus review of optimal perioperative care in colorectal surgery: Enhanced Recovery After Surgery (ERAS) Group recommendations. Arch Surg. 2009;144(10):961-9.
11. Gustafsson UO, Scott MJ, Schwenk W, Demartines N, Roulin D, Francis N, McNaught CE, Macfie J, Liberman AS, Soop M, Hill A, Kennedy RH, Lobo DN, Fearon K, Ljungqvist O, Enhanced Recovery After Surgery (ERAS) Society, for Perioperative Care, European Society for Clinical Nutrition and metabolism (ESPEN), International Association for Surgical Metabolism and Nutrition (IASMEN). Guidelines for perioperative care in elective colonic surgery: Enhanced Recovery After Surgery (ERAS $\left({ }^{\circledR}\right)$ ) Society recommendations. World J Surg. 2013;37(2):259-84.

12. Hasenberg $T$, Keese M, Längle F, Reibenwein B, Schindler K, Herold A, Beck G, Post S, Jauch KW, Spies C, Schwenk W, Shang E. 'Fast-track' colonic surgery in Austria and Germany-results from the survey on patterns in current perioperative practice. Colorectal Dis. 2009;11:162-7.

13. Fung AK, Aly EH. Systematic review of single-incision laparoscopic colonic surgery. Br J Surg. 2012;99:1353-64.

14. Guillou PJ, Quirke P, Thorpe H, Walker J, Jayne DG, Smith AM, Heath RM, Brown JM. Short-term endpoints of conventional versus laparoscopic-assisted surgery in patients with colorectal cancer (MRC CLASICC trial): multicentre, randomized controlled trial. Lancet. 2005;365:1718-26.

15. Schwenk W, Haase O, Neudecker J, Müller JM. Short term benefits for laparoscopic colorectal resection. Cochrane Database Syst Rev. 2005;20(3):CD003145(PMID: 16034888).

16. Lassen $\mathrm{K}$, Hannemann $\mathrm{P}$, Ljungqvist $\mathrm{O}$, Fearon $\mathrm{K}$, Dejong $\mathrm{CH}$, von Meyenfeldt MF, Hausel J, Nygren J, Andersen J, Revhaug A. Patterns in current perioperative practice: survey of colorectal surgeons in five northern European countries. BMJ. 2005;330:1420-1

17. Smith I, Kranke P, Murat I, Smith A, O'Sullivan G, Søreide E, Spies C, Veld B. European Society of Anaesthesiology. Perioperative fasting in adults and children: guidelines from the European Society of Anaesthesiology. Eur J Anaesthesiol. 2011;28(8):556-69.

18. Maessen J, Dejong CH, Hausel J, Nygren J, Lassen K, Andersen J, Kessels AG, Revhaug A, Kehlet H, Ljungqvist O, Fearon KC, von Meyenfeldt MF. A protocol is not enough to implement an enhanced recovery programme for colorectal resection. Br J Surg. 2007;94:224-31.

19. Ahmed J, Khan S, Lim M, Chandrasekaran TV, MacFie J. Enhanced recovery after surgery protocols-compliance and variations in practice during routine colorectal surgery. Colorectal Dis. 2012;14:1045-51.

20. Ahmed J, Khan S, Gatt M, Kallam R, MacFie J. Compliance with enhanced recovery programmes in elective colorectal surgery. Br J Surg. 2010;97:754-8.

21. Varadhan KK, Neal KR, Dejong CH, Fearon KC, Ljungqvist O, Lobo DN. The enhanced recovery after surgery (ERAS) pathway for patients undergoing major elective open colorectal surgery: a meta-analysis of randomized controlled trials. Clin Nutr. 2010;29(4):434-40.

22. Bona S, Molteni M, Rosati R, Elmore U, Bagnoli $\mathrm{P}$, Monzani R, Caravaca M, Montorsi M. Introducing an enhanced recovery after surgery program in colorectal surgery: A single center experience. World J Gastroenterol. 2014;20(46):17578-87.

23. Rawal N. Epidural technique for postoperative pain: gold standard no more? Reg Anesth Pain Med. 2012;37(3):310-7.

24. Keller DS, Stulberg JJ, Lawrence JK, Delaney CP. Process control to measure process improvement in colorectal surgery: modifications to an established enhanced recovery pathway. Dis Colon Rectum. 2014;57(2):194-200.

25. Abraham-Nordling M, Hjern F, Pollack J, Prytz M, Borg T, Kressner U. Randomized clinical trial of fluid restriction in colorectal surgery. Br J Surg. 2012;99(2):186-91. 
26. Srinivasa S, Lemanu DP, Singh PP, Taylor MH, Hill AG. Systematic review and meta-analysis of oesophageal Dopplerguided fluid management in colorectal surgery. Br J Surg. 2013;100(13):1701-8.

27. Hoffmann H, Kettelhack C. Fast-track surgery-conditions and challenges in postsurgical treatment: a review of elements of translational research in enhanced recovery after surgery. Eur Surg Res. 2012;49(1):24-34.
28. Mortensen K, Nilsson M, Slim K, et al. Consensus guidelines for enhanced recovery after gastrectomy: Enhanced Recovery After Surgery (ERAS ${ }^{\circledR}$ ) Society recommendations. Br J Surg. 2014;101(10):1209-29.

29. Coolsen MM, van Dam RM, van der Wilt AA. Systematic review and meta-analysis of enhanced recovery after pancreatic surgery with particular emphasis on pancreaticoduodenectomies. World J Surg. 2013;37(8):1909-18. 